\title{
Ege Bölgesine Uygun Pamuk (Gossypium hirsutum L.) Çeşitlerinde Verim ve Kalite Özelliklerinin Belirlenmesi
}

\section{ibrahim KÖKEN ${ }^{* 1}$ (D) Emre ILKER ${ }^{2}$}

\author{
${ }^{1}$ Niğde Ömer Halisdemir Üniversitesi Tarım Bilimleri ve Teknolojileri Fakültesi Tarımsal Genetik Mühendisliği \\ Bölümü, Niğde \\ ${ }^{2}$ Ege Üniversitesi Ziraat Fakültesi Tarla Bitkileri Bölümü, Bornova-Izmir
}

Öz: Pamuk bitkisi, yaygın ve zorunlu kullanım alanıyla iş ve ekonomi dünyası için; yarattığı katma değer ve iş olanaklarıyla da üretici ülkeler açısından büyük ekonomik değere sahip bir üründür. Son 20 yılda ülkemizde pamuk ekim alanlarında \% $45^{\prime}$ lik bir azalma söz konusudur. Ege Bölgesi'nde yaygın olarak ekilen birçok pamuk çeşidinin içinden bölgeye en çok adapte olmuş, yüksek lif kalitesine ve çırçır randımanına sahip çeşidin bulunması amacıyla yürütülen bu çalışma, 2016 - 2017 yetiştirme sezonunda Ege Üniversitesi Ziraat Fakültesi Tarla Bitkileri Bölümü Araştırma ve Uygulama arazisinde, tesadüf blokları deneme desenine göre dört tekrarlı olarak kurulmuştur. Denemede materyal olarak 12 pamuk çeşidi (Gloria, Claudia, Julia, ST 373, Karizma, Özaltın 404, Carmen, Sezener 76, Naz 07, Flash, BíR 949, Özbek 100) kullanılmıştır. Çalışmada; bitki boyu, bitkide koza sayısı, bitkide meyve dalı sayısı, kütlü verimi, lif verimi, çırçır randımanı, lif inceliği, lif mukavemeti, lif uzunluğu ve lif esnekliği olmak üzere 10 özellik incelenmiştir. Yapılan gözlemler ve analizler sonucunda bu 12 çeşit içerisinde en yüksek kütlü pamuk ve lif verimi Claudia ve Julia'dan elde edilmiştir. En yüksek lif uzunluğu ve lif mukavemeti değerleri BíR 949 çeşidinden elde edilmiştir. Sonuç olarak, ileride yapılacak melezleme çalışmalarının amacına göre Claudia ve BÍR 949 çeşitleri ümitvar olarak belirlenmiştir.

Anahtar Kelimeler: lif, çırçır, kütlü, koza, mukavemet

\section{Determination of Yield and Quality Properties of Suitable Cotton Varieties for Aegean Region}

\begin{abstract}
Cotton has a great economic value in terms of producer countries with added value and job opportunities that it creates for the industry and economy with its widespread and compulsory use. Over the past 20 years there has been a $45 \%$ reduction in cotton cultivation areas in our country. This study was carried out at the experimental area of the Department of Field Crops, Faculty of Agriculture, Ege University in 2016, in order to find the most adept species with high fiber quality and ginning capacity among the many cultivated cotton species in the Aegean Region. In this study, which was established as four replications according to the randomized complete blocks design, 12 cotton varieties (Gloria, Claudia, Julia, ST 373, Karizma, Özaltın 404, Carmen, Sezener 76, Naz 07, Flash, BiR 949, Özbek 100). ). In this study, plant height, number of boll, number of fruiting branch, cotton seed yield, fiber yield, ginning turnout, fiber tenderness, fiber strength, fiber length and fiber flexibility were examined. As a result of the observations and fiber analyzes, it was seen that among these 12 varieties, the highest seed cotton yield and fiber yield were obtained from Claudia and Julia varieties. The highest fiber length and fiber strength were obtained from BiR 949. As a final, Claudia and BiR 949 have been detected as promising varieties according to purpose of future hybridization studies.
\end{abstract}

Keywords: fiber, ginning, cotton seed yield, boll, endurance

\section{GíRiş}

Eski Dünya'ya özgü olan diploid türler; Gossypium arboreum

L. ve G. herbaceum L. ile yeni Dünya'da ortaya çıkan allotetraploid türler; G. barbadense L. ve G. hirsutum G. arboreum. Hindistan'da önemli bir ürün olarak kalırken, daha önceki zamanlarda önemli olan $G$. herbaceum, bugün Afrika ve Asya'nın daha kurak bölgelerinde çoğunlukla yerel kullanım için yetiştirilmektedir. Yaygın olarak Mısır Pamuğu ve Pima pamuğu olarak bilinen $G$. barbadense, şu andaki dünya lif üretiminin yaklaşık \%3 ile 5'ini sağlamaktadır (Lee and Fang, 2015). Verim değerleri ortalamaya göre yüksek potansiyelli, vejetasyon süresi orta-uzun olan, çırçır randımanı genelde $\% 40$ seviyelerinde olan G. hirsutum türü dünyada yetiştiriciliği yapılan pamukların yaklaşık \%95'ini oluşturmaktadırlar. Bu sebepten dolayı da ülkemizde yetiştiriciliği yapılan pamuk çeşitlerinin tamamı G. hirsutum L. türüne aittir (Akdemir ve ark., 2001). Uygulanan farklı pamuk üretim teknikleri ve ekolojik farklılıklar, pamuk tarımı yapılan bölgelerimizde yetiştirilen çeşitlerin birbirlerinden oldukça farklı özelliklere sahip olmasına sebep olmuştur. Günümüzde pamuk üretimindeki temel amaçlar yüksek kütlü ve çırçır verimi yanında lif teknolojik özelliklerinin geliştirilmesi, erkencilik, hastalık ve zararlılara karşı mukavemet ve üretim masraflarının azaltılabilmesi şeklinde özetlenebilir (Gençer ve ark., 2005).

Üretim girdilerinin oldukça fazla olması, devlet tarafından verilen teşviklerin girdi masraflarını karşılamada yeterli

Sorumlu Yazar: ibrahimkoken@ohu.edu.tr. Bu çalışma yüksek lisans tez ürünüdür ve Ege Üniversitesi Bilimsel Araştırma Projeleri Komisyonu tarafından desteklenmiştir (Proje No: 16-ZRF-061)

Geliş Tarihi: 3 Eylül 2019

Kabul Tarihi: 25 Nisan 2020 
olmayışı nedeniyle elde edilen net gelirin düşüklüğü ve dünya pamuk fiyatlarındaki düşüşün ithal pamuğu daha avantajlı hale getirmesi nedenleriyle üretici pamuk ekiminden vazgeçmeye başlamış ve bu durumun sonucunda Ege Bölgesi'nde pamuk üretim alanlarında önemli bir düşüş yaşanmıştır (ilker ve ark., 2008).

Ülkemizde tekstil sanayinin talebi olan pamuğu karşılamak ve pamuk tarımını sürdürülebilir hale getirmek için; ekim alanlarının arttırılması veya birim alandan alınan kütlü miktarının arttırılması gerekmektedir. Ancak ülkemizin bulunduğu coğrafik konum sebebiyle son yıllarda gerçekleşen pamuk üretim maliyeti ve piyasa fiyatları göz önüne alındığında ekim alanlarının arttırılmasının bir hayli güç olduğu görülmektedir (Özbek ve ark., 2009).

Çizelge 1 'de yer alan son 5 üretim sezonu ortalamaları incelendiğinde ülkemizde üretilen pamuk lifi miktarı, tükettiğimizin yarısını ancak karşılayabilmektedir. 2012/13 sezonunda bu oran \%63 iken hem üretimdeki azalış hem de

Çizelge 1. Türkiye pamuk lifi üretim ve tüketimi

\begin{tabular}{lcccc}
\hline Yıl & Üretim (bin ton) & Tüketim (bin ton) & Fark ((bin ton) & Üretim - Tüketim Fark Oranı (\%) \\
\hline $2012 / 13$ & 858 & 1360 & -502 & 63.0 \\
$2013 / 14$ & 877 & 1400 & -640 & 62.6 \\
$2014 / 15$ & 846 & 1486 & -525 & 56.9 \\
$2015 / 16$ & 738 & 1500 & -762 & 49.2 \\
$2016 / 17$ & 756 & 1450 & -694 & 52.1 \\
\hline
\end{tabular}

Kaynak: Anonim, 2017a

\section{MATERYAL VE YÖNTEM}

Ege Üniversitesi Ziraat Fakültesi Tarla Bitkileri Bölümü'nün araştırma ve uygulama alanlarında yürütülen çalışmada materyal olarak bölgede yaygın olarak ekilen, ana özellikleri birbirinden farklı olan 12 pamuk çeşidi (Gloria, Claudia, Julia, ST 373, Karizma, Özaltın 404, Carmen, Sezener 76, Naz 07, Flash, BíR 949, Özbek 100) kullanılmıştır.

Denemenin yapıldığı İzmir ìli Bornova İlçesi'nde, 2016 yılı Mayıs-Ekim ayları arasını içeren bitki gelişim periyodu süresince ortalama sıcaklık değerlerinin $29.3^{\circ} \mathrm{C}$ (Temmuz) ile $19.4^{\circ} \mathrm{C}$ (Kasım) arasında seyretmiştir. Yapılan toprak analizinde ise deneme arazisindeki toprak yapısının killi tın bünyeye sahip olduğu, $\mathrm{pH}$ değerinin hafif alkali ve tuz tüketimdeki artış sebebiyle 2016/17 sezonunda \%52.1 seviyesine kadar düşmüştür.

Ekim alanlarının arttırılamayacağı göz önüne alındığında pamuk bitkisinden alınan verimi arttırmak elzemdir. Bu çerçevede yapılacak çalışmalar içinde en önemli olan; birim alandan lif kalitesi yüksek daha fazla ürün elde edilmesini amacıyla yürütülen pamuk ıslah çalışmalarıdır. Pamuk ıslahında yegâne amaçlardan biri üstün verim ve lif kalite parametrelerine sahip çeşitlerin geliştirilmesidir. Başarılı bir ıslah programında ilk adım uygun ebeveynlerin seçimidir (Gençer, 1978; Başal ve Turgut, 2003).

Bu çalışmada, Ege Bölgesi'nde yaygın olarak tarımı yapılan pamuk çeşitleri materyal olarak seçilmiş olup bu çeşitler içinde verim ve kalite bakımından öne çıkan çeşitlerin belirlenmesi amaçlanmıştır. Elde edilen sonuçlar ışığında; verim bakımından öne çıkan çeşitlerin ebeveynlerden biri, kalite bakımından öne çıkanlar çeşitlerin de ebeveynlerden diğeri olacak şekilde bir planlanacak bir melezleme programına ön hazırlık oluşturması hedeflenmiştir.

Çizelge 2. Araştırma yeri toprağının bazı fiziksel ve kimyasal özellikleri

\begin{tabular}{llllll}
\hline Özellikler & $\mathbf{0 - 3 0 ~} \mathbf{c m}$ & Yorum & Özellikler & $\mathbf{0 - 3 0 ~ c m ~}$ & Yorum \\
\hline Kum (\%) & 24.72 & 24.72 & Eriyebilir toplam tuz (\%) & 0.0172 & hafif tuzlu \\
Kil (\%) & 32.56 & - & Organik madde (\%) & 1.24 & fakir \\
Mil (\%) & 42.72 & - & Toplam azot (\%) & 0.11 & orta \\
Bünye & Tın & - & Faydalı fosfor (ppm) & 2.43 & orta \\
pH & 7.84 & Hafif alkali & Faydalı potasyum (ppm) & 284 & orta \\
Kireç (\%) & 9.91 & Orta kireçli & Faydalı kalsiyum (ppm & 2100 & normal \\
\hline
\end{tabular}

değerlerinin ise bitki yetiştiriciliği açısından bir sorun olmayacak düzeyde olduğu belirlenmiştir (Çizelge 2)

Deneme yerinin iklim özelliklerine ilişkin ölçümler Çizelge 3'de verilmiştir. iklimsel veriler denemede pamuğun yetiştirildiği periyoda aittir.

İklim verilerine incelendiğinde, denemenin arazide kaldığı süre boyunca sıcaklık ortalamalarının, uzun yıllar sıcaklık ortalamasıyla büyük farklılıklar göstermediği, ancak yağış değerlerinin uzun yıllar ortalamasının oldukça altında olduğu görülmektedir.

Deneme, tesadüf blokları deneme desenine göre dört tekrarlı olarak kurulmuştur. Toplam 48 parselden oluşan denemede her bir pamuk çeşidi, $7 \mathrm{~m}$ uzunluğunda üç sıra, 
Çizelge 3. Araştırma yerine ait bazı iklim özellikleri (Anonim, 2017b)

\begin{tabular}{lllll} 
& $\mathbf{2 0 1 6}$ & & Uzun Yıl Ortalaması & \\
\cline { 2 - 5 } & Ortalama Sıcaklık $\left({ }^{\circ} \mathrm{C}\right)$ & Toplam Yağış $(\mathrm{mm})$ & Ortalama Sıcaklık $\left({ }^{\circ} \mathrm{C}\right)$ & Toplam Yağış (mm) \\
\hline Nisan & 18.9 & 28.8 & 16.1 & 46.4 \\
Mayıs & 20.7 & 38.6 & 21.0 & 25.4 \\
Haziran & 27.5 & 2.8 & 26.0 & 7.5 \\
Temmuz & 29.3 & - & 28.3 & 2.1 \\
Ağustos & 28.9 & 0.2 & 27.9 & 1.7 \\
Eylül & 24.7 & 8.6 & 23.9 & 19.9 \\
Ekim & 19.7 & 0.5 & 19.1 & 43.2 \\
\hline
\end{tabular}

$70 \mathrm{~cm}$ sıra arası ve $20 \mathrm{~cm}$ sıra üzeri esasına göre 15 Mayıs 2016 tarihinde ekilmiştir. Her bir pamuk çeşidine ait parsel boyutları $2.1 \times 7=14.7 \mathrm{~m}^{2}$ olup bir bloğa ait toplam alan $14.7 \times 12=176.4 \mathrm{~m}^{2}$ dir. Bloklar arasında ise 1 metre olup toplam deneme alanı (blok araları dâhil) $894.6 \mathrm{~m}^{2}$ den oluşmaktadır. Çıkıştan sonra, sıra üzerindeki bitkiler arasında $20 \mathrm{~cm}$ boşluk bırakacak şekilde seyreltme yapılmıştır. Gübreleme; ekim sırasında sulu koşullarda yaklaşık dekar başına $15 \mathrm{~kg}$ azot, $6 \mathrm{~kg}$ dolayında ise fosfor esasına göre DAP formunda uygulanmıştır (Mert, 2009). Denemede can suyu dışında ilk sulama ekimden 30 gün sonra yapılmış olup daha sonrasında hasada kadar 5 sulama yapılmıştır. Denemede bir defa çapalama makinasıyla iki defa elle olmak üzere üç defa çapalama işlemi yapılmıştır. Yabancı ot mücadelesi için bitkiler çiçek açmadan önce iki kez herbisit uygulaması yapılmıştır. Araştırmada bitki boyu, bitkide meyve dalı sayısı, kütlü pamuk verimi, lif verimi, çırçır randımanı, lif inceliği, lif mukavemeti, lif uzunluğu, lif esnekliği olmak üzere 10 özellik incelenmiştir.

Incelenen özelliklerden kütlü verimi, lif verimi ve çırçır randımanı; her parseldeki tüm bitkilerin tek elde hasat edilip, hasat edilen kütlülerin tartıldıktan sonra verilerin dekara çevrilmesiyle bulunmuştur. Verim için önemli bir unsur kabul edilen bitki başına meyve dalı sayısı, parseli temsil eden ardışık 10 bitkinin meyve dalları sayılıp ortalaması alınarak belirlenmiştir. Lif inceliği, lif mukavemeti, lif uzunluğu ve lif esnekliği değerlerini bulmak için her parselden alınan lif örnekleri USTER HVI 1000 cihazı ile ölçülmüştür.

Denemede, 12 pamuk çeşidinin incelenen özelliklerine ait veriler Tesadüf Blokları Deneme Desenine göre 'TOTEMSTAT' programı kullanılarak varyans analizine sokulmuş olup değerler arasındaki farklar ise LSD testi karşılaştırma yöntemine göre gruplandırılmıştır (Açıkgöz ve ark., 2004).

\section{BULGULAR VE TARTIŞMA}

İncelenen özelliklere ilişkin varyans analizi sonuçları Çizelge 4'de verilmiştir.

Bitki Morfolojik Parametreleri (Bitki Boyu - Bitki Koza Sayısı - Bitki Meyve Dalı Sayısı)

Çizelge 5'de verilen LSD gruplandırmasında Özbek 100 (88.6 $\mathrm{cm}$ ) çeşidinin en yüksek bitki boyuna sahip olduğu görülmüştür En kısa bitki boyuna ise $65.9 \mathrm{~cm}$ ile Claudia çeşidinin sahip olduğu görülmüştür. Çopur ve Yuka (2016), buğday sonrası ikinci ürün olarak yetiştirilen pamuk çeşitlerinin verim ve verim unsurlarını inceledikleri çalışmada bitki boyunu 83.53-119.27 cm olarak saptamışlardır. İkinci ürün yetiştirme koşullarında vejetasyon süresi kısa olduğu için orta erkenci ve geçci çeşitler daha çok vejetatif olarak gelişmekte ve farklı bitki boyu grupları oluşabileceği belirtilmiştir.

Verim için en önemli parametrelerden biri olan koza sayısı incelendiğinde; bitki boyunda olduğu gibi Özbek 100 çeşidi (20.9 adet /bitki) en yüksek koza sayısı ortalamasına sahiptir. Bitki başına koza sayısı kütlü pamuk verimi için önemli bir parametredir. Araştırmada elde edilen veriler Akışcan (2011)'ın 13.9-22.27 adet/bitki ortalamasıyla uyumludur.

Çizelge 5'de verilen LSD gruplandırmasına göre bitki başına en yüksek meyve dalı sayısı ortalamasına sahip çeşit Özbek 100 (15.8 adet/bitki) olmuştur. En düşük meyve dalı sayısı ortalamasına sahip çeşitler Sezener 76 (10.1 adet/bitki) ve Flash (10.3 adet/bitki) olmuştur. Pamuk bitkisinde meyve ve odun dalı olmak üzere iki tip dal bulunmaktadır. Odun dalları vejetatif organlar olup üzerinde koza bulundurmazken meyve dalları generatif organ özelliği

Çizelge 4. İncelenen özelliklere ilişkin varyans analizi ile hesaplanan kareler ortalaması

\begin{tabular}{|c|c|c|c|c|c|c|c|c|c|c|c|}
\hline $\begin{array}{l}\text { Varyasyon } \\
\text { Kaynağı }\end{array}$ & S.D & Bitki Boyu & $\begin{array}{l}\text { Koza } \\
\text { Sayısı } \\
\text { (Adet/ } \\
\text { Bitki) }\end{array}$ & $\begin{array}{l}\text { Meyve } \\
\text { Dalı } \\
\text { Sayısı } \\
\text { (Adet/ } \\
\text { Bitki) }\end{array}$ & $\begin{array}{l}\text { Kütlü Pamuk } \\
\text { Verimi } \\
\text { (kg/da) }\end{array}$ & $\begin{array}{l}\text { Lif Verimi } \\
(\mathrm{kg} / \mathrm{da})\end{array}$ & $\begin{array}{l}\text { Çırçır } \\
\text { Randı- } \\
\text { manı } \\
(\%)\end{array}$ & $\begin{array}{l}\text { Lif } \\
\text { İnceliği } \\
\text { (mic) }\end{array}$ & $\begin{array}{l}\text { Lif } \\
\text { Mukave } \\
\text {-meti } \\
\text { (gr/tex) }\end{array}$ & $\begin{array}{l}\text { Lif } \\
\text { Uzunlu- } \\
\text { ğu } \\
(\mathrm{mm})\end{array}$ & $\begin{array}{l}\text { Lif } \\
\text { Esnekli- } \\
\text { ği (\%) }\end{array}$ \\
\hline Tekerrür & 3 & $352.63^{* *}$ & $10.54 * *$ & $16.25^{* *}$ & 40657.14* & 11793.77 & 8.48 & 0.03 & 2.67 & $3.36^{*}$ & 0.25 \\
\hline Çeşit & 11 & $185.50 * *$ & $34.44 * *$ & $13.51^{* *}$ & 396537.09** & $98805.43 * *$ & $25.95^{* *}$ & $0.25 * *$ & $22.00 * *$ & $7.06 * *$ & $2.79 * *$ \\
\hline Hata & 33 & 53.90 & 0.92 & 2.60 & 13075.75 & 6831.14 & 5.66 & 0.03 & 3.18 & 0.90 & 0.29 \\
\hline Genel & 47 & & & & & & & & & & \\
\hline
\end{tabular}


Ege Bölgesine Uygun Pamuk (Gossypium hirsutum L.) Çeşitlerinde Verim ve Kalite Özelliklerinin Belirlenmesi

Çizelge 5. Çeşitlerin gözlemlenen özelliklere ait ortalamaları ve LSD gruplandırması

\begin{tabular}{|c|c|c|c|c|c|c|c|c|c|c|}
\hline Çeşitler & $\begin{array}{l}\text { Bitki } \\
\text { Boyu (m) }\end{array}$ & $\begin{array}{l}\text { Koza Sayısı } \\
\text { (adet/ } \\
\text { bitki) }\end{array}$ & $\begin{array}{l}\text { Meyve Dalı } \\
\text { Sayısı } \\
\text { (adet/bitki) }\end{array}$ & $\begin{array}{l}\text { Kütlü } \\
\text { Verimi } \\
\text { (kg/da) }\end{array}$ & $\begin{array}{l}\text { Lif Verimi } \\
(\mathrm{kg} / \mathrm{da})\end{array}$ & $\begin{array}{l}\text { Çırçır } \\
\text { Randımanı } \\
(\%)\end{array}$ & $\begin{array}{l}\text { Lif } \\
\text { İnceliği } \\
\text { (mic) }\end{array}$ & $\begin{array}{l}\text { Lif } \\
\text { Mukave- } \\
\text { meti } \\
\text { (gr/tex) }\end{array}$ & $\begin{array}{l}\text { Lif } \\
\text { Uzunluğu } \\
(\mathrm{mm})\end{array}$ & $\begin{array}{l}\text { Lif } \\
\text { Esnekliğ } \\
(\%)\end{array}$ \\
\hline Gloria & 75.6 BCDEF & $13.5 \mathrm{DE}$ & $11,5 \mathrm{DE}$ & $439.6 \mathrm{~A}$ & $185.9 \mathrm{ABC}$ & $42.3 \mathrm{ABCD}$ & $5.6 \mathrm{AB}$ & $34.2 \mathrm{AB}$ & $28.8 \mathrm{BC}$ & $4.6 \mathrm{DEF}$ \\
\hline Claudia & $65.9 \mathrm{~F}$ & $13.7 \mathrm{D}$ & $13,4 \mathrm{BCD}$ & $468.2 \mathrm{~A}$ & 209.9 A & $44.8 \mathrm{~A}$ & $5.6 \mathrm{~A}$ & $33.8 \mathrm{ABC}$ & 29.5 B & $4.3 \mathrm{EF}$ \\
\hline Julia & $72.9 \mathrm{DEF}$ & $17.2 \mathrm{C}$ & $14,7 \mathrm{ABC}$ & $461.5 \mathrm{~A}$ & 207.7 AB & $45.0 \mathrm{~A}$ & $5.6 \mathrm{~A}$ & $35.5 \mathrm{AB}$ & $29.0 \mathrm{~B}$ & 4.7 DEF \\
\hline Carmen & $70.4 \mathrm{EF}$ & $17.1 \mathrm{C}$ & $13,3 \mathrm{BCD}$ & $370.4 \mathrm{BC}$ & 159.9 DE & $43.2 \mathrm{ABC}$ & $5.4 \mathrm{BC}$ & $36.2 \mathrm{~A}$ & 29.3 B & $4.0 \mathrm{~F}$ \\
\hline Flash & 78.7 ABCDE & 19.7 AB & $10,3 \mathrm{E}$ & $307.8 \mathrm{D}$ & 121.0 FG & 39.3 DEF & $5.7 \mathrm{~A}$ & $35.7 \mathrm{AB}$ & 29.1 B & $5.3 \mathrm{CD}$ \\
\hline ST373 & $75.1 \mathrm{CDEF}$ & $12.3 \mathrm{E}$ & $14,6 \quad A B C$ & $347.6 \mathrm{C}$ & 142.0 EF & 40.9 BCDEF & $5.2 \mathrm{C}$ & $31.4 \mathrm{CDE}$ & 29.0 B & $5.8 \mathrm{BC}$ \\
\hline Karizma & 73.9 DEF & 19.1 B & $14,8 \quad A B$ & $437.0 \mathrm{~A}$ & $183.6 \mathrm{BCD}$ & $42.0 \mathrm{ABCDE}$ & $5,2 \mathrm{C}$ & $30.0 \mathrm{E}$ & $27.6 \mathrm{CD}$ & $7.0 \mathrm{~A}$ \\
\hline BíR 949 & $85.3 \mathrm{ABC}$ & 12.4 DE & $12,4 \mathrm{CDE}$ & 387.2 B & $148.8 \mathrm{E}$ & $38.4 \mathrm{~F}$ & $4.9 \mathrm{D}$ & $36.0 \mathrm{AB}$ & $32.1 \mathrm{~A}$ & $5.0 \mathrm{CDE}$ \\
\hline Öz 404 & $81.6 \mathrm{ABCD}$ & $16.5 \mathrm{C}$ & $12,3 \quad \mathrm{DE}$ & $461.6 \mathrm{~A}$ & $187.0 \mathrm{ABC}$ & $40.5 \mathrm{CDEF}$ & $5.2 \mathrm{C}$ & $33.6 \mathrm{BCD}$ & $29.6 \mathrm{~A}$ & $5.2 \mathrm{CD}$ \\
\hline Özbek 100 & $88.6 \mathrm{~A}$ & $20.9 \mathrm{~A}$ & $15,8 \mathrm{~A}$ & $469.5 \mathrm{~A}$ & $182.5 \mathrm{CD}$ & $38.9 \mathrm{EF}$ & $5.2 \mathrm{C}$ & $30.1 \mathrm{E}$ & $27.1 \mathrm{D}$ & 4.7 DEF \\
\hline Sezener 76 & $75.3 \mathrm{CDEF}$ & $13.5 \mathrm{DE}$ & $10,1 E$ & 291.7 BC & $108,9 \mathrm{G}$ & $37.3 \mathrm{~F}$ & $5.3 \mathrm{C}$ & $35.4 \mathrm{AB}$ & 29.1 B & $5.1 \mathrm{CD}$ \\
\hline Naz 07 & $86.1 \mathrm{AB}$ & $16.0 \mathrm{C}$ & $11,7 \quad \mathrm{DE}$ & $362.8 \mathrm{BC}$ & 160.4 DE & $44.2 \mathrm{AB}$ & $5.2 \mathrm{C}$ & $31.2 \mathrm{DE}$ & $28.6 \mathrm{BC}$ & $6.3 \mathrm{AB}$ \\
\hline
\end{tabular}

taşıyıp üzerinde çiçekleri bulundurur. Meyve dalı sayısının fazla olması, yüksek verim için istenen bir özelliktir (Fry, 1985; Efe ve ark., 2004). Özkan ve Kaynak (2009), meyve dallarının verim, verim unsurları ve lif kalite özelliklerine etkisinin saptanması amacıyla yaptıkları çalışmada, meyve dallarındaki kütlü pamuk verimi, koza kütlü ağırlığı, lif uzunluğu ve lif mukavemeti özelliklerinin 7. meyve dalına kadar üstün olduğu; çırçır randımanının ve lif inceliğinin 6 . ile 10. meyve dallarında üstün olduğunu belirlemiştir. Baran (2013), pamukta ekim zamanı geciktikçe oluşan meyve dalı sayısının azaldığını gözlemlemiştir. Buna paralel olarak Kaynak ve Çopur (1999) ile Söyler ve Temel (2007) de ekimin gecikmesiyle meyve dalı sayılarının azalacağını bildirmektedirler.

\section{Verim Parametreleri( Kütlü Verimi - Lif Verimi - Çırçır Randımanı)}

Özbek 100 (469.52 kg/da), Claudia (439.61 kg/da), Julia (461.54 kg/da), Gloria (439.61 kg/da) ve Karizma (437 $\mathrm{kg} / \mathrm{da}$ ) çeşitleri en yüksek kütlü verimine ulaşan çeşitler olurken, en düşük kütlü verimi Flash $(370.37 \mathrm{~kg} / \mathrm{da})$ çeşidine aittir. Gloria, Claudia, Julia ve Carmen çeşitleri bitki boyu, koza sayısı, meyve-odun dalı sayısı gibi parametrelerde düşük değerler vermesine karşılık kütlü veriminde öne çıkan çeşitler olmuştur. Özbek 100 genotipinin koza sayısı yönüyle olan üstünlüğünün lif verimine yansımadığı görülmüştür (Çizelge 5). (Mustafayev ve ark., 2014), Azerbaycan'da elde ettikleri bazı mutant pamuk çeşitlerinin Şanlıurfa koşullarında verim ve lif kalite özelliklerini değerlendirdikleri çalışmada kütlü verimini 320.5-396.2 $\mathrm{kg} /$ da değerleri arasında bulmuşlardır. Yapılan çalışmada yüksek kütlü verimine sahip olan çeşitlerin meyve dalı sayısının da yüksek olduğu tespit edilmiştir.

Lif endüstrisi için üretim yapacak çiftçiler için en önemli parametre olan lif verimi değerlerinde öne çıkan çeşit Claudia (209.9 kg/da) olmuştur. En düşük lif verimi ortalamasına sahip çeşit ST 373 (142 kg/da) olmuştur (Çizelge 5).
Çizelge 5'de verilen LSD gruplandırmasına göre en fazla çırçır randımanı ortalamasına sahip çeşitler Julia (\%45) ve Claudia (\%44.8) olmuştur. En düşük çırçır randımanı ortalamasına sahip çeşitler Sezener 76 (\%37.3) ve Bir 949 (\%38.4) olmuştur.

Lif Kalite Parametreleri (Lif İnceliği - Lif Mukavemeti - Lif Uzunluğu - Lif Esnekliği)

Pamuk bitkisinin lifleri, uzunluk, mukavemet, incelik ve esneklik gibi çok çeşitli fiziksel özellikler, çeşitten çeşide önemli farklılıklar gösterir (Majumdar ve ark., 2004).

Çizelge 5'deki lif kalite parametrelerinden lif inceliği değerleri incelendiğinde Flash $(5.7 \mathrm{mic}$ ) çeşidinin en kaba lif inceliği, Bir 949 (4.9 mic) çeşidinin ise en ince lif inceliğine sahip olduğu görülmüştür.

Tekstil sanayisinde istenilen bir özellik olan lif mukavemeti (dayanıklılığı) değerlerine ele alındığında Carmen (36.2 g/tex) ve Bir 949 (36.0 g/tex) en dayanıklı liflere sahip çeşitler olurken, Karizma çeşidi (30.0 g/tex) en düşük lif dayanıklılığına sahip çeşit olmuştur.

Pamuk lifinin uzunluğu, dayanıklılık konusunda olduğu gibi, ne kadar uzun olursa o kadar iyidir. Esas uzunluk temel olarak türe göre belirlenirken, çevresel faktörler, türün mümkün olan en yüksek uzunluğa erişme kapasitesini etkileyebilir. Esas uzunluk için önemli stres faktörleri, yüksek sıcaklıklar ve potasyum eksikliğidir (Anonim, 2013). Çiçeklenme döneminin başlangıç aşamasındaki su stresinin lif uzunluğunu önemli derecede etkilemese de çiçeklenme başlangıç döneminden hemen sonraki dönemde ortaya çıkan su eksikliğinin hücre uzaması üzerine olan olumsuz mekanik ve fizyolojik etkilerinden dolayı lif uzunluğunu olumsuz etkilediği belirtilmiştir (Bradow ve Davidonis, 2000; McWilliams, 2003; Hussein ve ark., 2011). Bir 949 çeşidi (32.1 mm) diğer 12 çeşide göre oldukça yüksek lif uzunluğu değerlerine sahip çeşit olurken, Özbek 100 (27.1 mm) en düşük lif uzunluğuna sahip çeşit olmuştur (Çizelge 5).

Lif esnekliği, bir ipliğin gerilim altında boyunun uzaması ve gerilim kalktığında eski uzunluğuna tamamen ya da kısmen dönebilme kabiliyetidir. Kritik uzama noktasına kadar 
uzatılmış yani kopma noktasına gelmiş bir ipliğin o anki erişmiş olduğu uzunluğun, serbest haldeki uzunluğuna oranlanmasıdır (Mert, 2009). Tekstil sanayisinde yüksek olması istenen bir özellik olan lif esnekliği açısından en yüksek değere Karizma çeşidi (\%7.0) ulaşırken en düşük lif esnekliği değerine ise Carmen çeşidi (\%4.0) sahip olmuştur.

\section{SONUÇ}

12 farklı pamuk çeşidinde toplam 10 parametrenin incelendiği çalışmada, Özbek 100 çeşidinin kütlü verimi açısından diğer çeşitlere göre üstünlük sağladığı ancak lif verimi açısından aynı durumun söz konusu olmadığı görülmüştür. Bunun sebeplerinden biri, Özbek 100 çeşidinin çırçır randımanının diğer çeşitlere göre düşük (\%38.9) olması gösterilebilir. Diğer bir sebep ise, Özbek 100'ün bitki başına meyve dalı sayısı en yüksek olan çeşit olmasına rağmen hasat öncesi olumsuz hava koşulların koza dökülmesine neden olması gösterebilir. Kütlü pamuk veriminde Claudia ve Julia çeşitleri ön plana çıkarken, lif veriminde ise Claudia çeşidi en yüksek değere ulaşmıştır. Tüm verim parametrelerinde ön planda olan Claudia çeşidi lif kalite parametrelerinde ise ortalama değerler vermiştir. Lif kalite kriterleri bakımından ise Bir 949 çeşidi, lif inceliği, lif mukavemeti ve lif uzunluğu değerlerinde diğer 11 çeşide göre en yüksek değerleri vermiştir. Sonuç olarak, ileride yapılacak melezleme çalışmalarının amacına göre Claudia ve BIR 949 çeşitleri ümitvar olarak belirlenmiştir.

\section{TEŞEKKÜR}

Bu araştırma, 16-ZRF-061 No'lu proje ile Ege Üniversitesi Bilimsel Araştırma Projeleri Komisyonu tarafından desteklenmiştir. Kuruma desteklerinden dolayı teşekkürü borç biliriz.

\section{KAYNAKLAR}

Açıkgöz N, İlker E, Gökçöl A (2004) Biyolojik Araştırmaların Bilgisayarda Değerlendirilmeleri. Ege Üniversitesi Yayınları, İzmir.

Akdemir H Gürel A, Karadayı HB (2001) Ege Bölgesi Koşullarına Uygun Uzun-İnce Elyaflı Pamukların Adaptasyonu Üzerine Araştırmalar. Anadolu Ege Tarımsal Araştırma Enstitüsü Dergisi 11(2): 56-75.

Akışcan Y (2011) Pamukta (Gossypium hirsutum L.) Verticillium Solgunluğu (Verticillium dahliae Kleb.) Hastalığına Dayanıklılık, Erkencilik, Verim ve Kalite Özelliklerinin Kalıtımı. Doktora Tezi, Çukurova Üniversitesi, Adana.

Anonim (2013) Better Cotton Açıklamalı Üretim Esasları ve Kriterleri, İyi Pamuk Uygulamaları Derneği, İstanbul.

Anonim (2017a) Türkiye'de Tekstilde Kullanılan Bitki Ürünleri. Türkiye İstatistik Kurumu, Ankara.

Anonim (2017b) Bornova İstasyonu Verileri. Meteoroloji 2. Bölge Müdürlüğü, İzmir.

Baran FO (2013) İkinci Ürün Koşullarında Farklı Ekim Zamanlarının Pamuğun (Gossypium hirsutum L.) Agronomik ve Teknolojik Özellikleri Üzerine Etkisi. Yüksek Lisans Tezi, Adnan Menderes Üniversitesi, Aydın.

Başal H, Turgut i (2003) Heterosis and Combining Ability for Yield Components and Fiber Quality Parameters in a Half Diallel Cotton (G. hirsutum L.) Population. Turkish Journal of Agriculture and Forestry 27(4): 207-212.
Bradow JM, Davidonis GH (2000) Quantitation of Fiber Quality and the Cotton Production-Processing Interface: a Physiologist's Perspective. J. Cotton Sci 4(1): 34-64.

Çopur O, Yuka A (2016). Buğday Sonrası İkinci Ürün Olarak Yetiştirilen Pamuk (Gossypium hirsutum L.) Çeşitlerinde Verim ve Verim Unsurlarının Belirlenmesi. Yüzüncü Yıl Üniversitesi Tarım Bilimleri Dergisi 26(2): 245-253.

Efe L, Killi F, Mustafayev SA (2004) Performance Evaluation of Some Earlier Yielding Mutant Cotton (Gossypium Spp.) Varieties in The East Mediterranean Region of Turkey. Pakistan Journal of Biological Sciences 7(5): 689-697.

Fry KE (1985). Earliness Factors in Three Pima Cotton Genotypes. Crop Science 25: 1020-1022.

Gençer O (1978) Gossypium hirsutum L. ve Gossypium barbadense L. Türlerinden Sekiz Pamuk Çeşidinin Diallel Melezlerinde Verim ve Kalite ile İlgili Başlıca Özelliklerin Kalıtımı Üzerine Araştırmalar. Doçentlik Tezi, Çukurova Üniversitesi, Adana.

Gençer O, Özüdoğru T, Kaynak MA, Yılmaz A, Ören N (2005) Türkiye'de Pamuk Üretimi Ve Sorunları. T. Özüdoğru, M.A. Kaynak, A. Yılmaz, N. Ören (Derl.), TMMOB Ziraat Mühendisleri Odası, Ankara.

Hussein F, Janat M, Yakoub A (2011) Assessment of Yield and Water Use Efficiency of Drip-Irrigated Cotton (Gossypium hirsutum L.) as Affected by Deficit Irrigation. Turkish Journal of Agriculture and Forestry 35(6): 611-621.

İlker E, Altınbaş M, Tosun M, Sakinoğlu FÇ (2008) İki Pamuk Melezinin (Gossypium spp.) F2 Generasyonunda Bazı Verim ve Lif Özellikleri İçin Heterosis ve Genotipik Değişkenlik. Ege Üniversitesi Ziraat Fakültesi Dergisi 45(3): 153-163.

Kaynak MA, Çopur O (1999) Makineli Hasada Uygun Pamuk Yetiştirme Tekniği. Harran Üniversitesi Ziraat Fakültesi Dergisi, 3(1): 67-76.

Lee JA, Fang DD (2015) Cotton as a World Crop: Origin, History, and Current Status. Cotton 1-23. doi: 10.2134/agronmonogr57.2013.0019.

Majumdar A, Sarkar B, Majumdar, PK (2004) Application of Analytic Hierarchy

Process for the Selection of Cotton Fibers. Fibers and Polymers 5(4): 297-302.

McWilliams D (2003) Drought strategies for cotton, cooperative extension service circular 582, College of Agriculture and Home Economics. New Mexico State University, USA.

Mert M (2009) Lif Bitkileri, Nobel Yayın Dağıtım, Ankara.

Mustafayev SA, Efe L, Kıllı F (2014). Azerbaycan'da Elde Edilmiş Bazı Mutant Pamuk (Gossypium hirsutum L.) Çeşitlerinin Şanlıurfa Koşullarında Verim ve Lif Kalite Özelliklerinin Değerlendirilmesi. Akdeniz Üniversitesi Ziraat Fakültesi Dergisi 18(2): 245-250.

Özbek N, Ekşi i, Erdoğan O (2009) Melezleme Islahı ile Erkenci Pamuk Çeşitlerinin Elde Edilmesi. Türkiye VIII. Tarla Bitkileri Kongresi, 19-22 Ekim 2009, Hatay 1: 747-751. 
Ege Bölgesine Uygun Pamuk (Gossypium hirsutum L.) Çeşitlerinde Verim ve Kalite Özelliklerinin Belirlenmesi

Özkan I, Kaynak, MA (2009). Farklı Pamuk (Gossypium hirsutum L.) Çeşitlerinde Meyve Dallarının, Verim, Verim Unsurları ve Lif Kalite Özelliklerine Etkisinin Saptanması. Adnan Menderes Üniversitesi Ziraat Fakültesi Dergisi 6(2): 47-55.
Söyler D, Temel N (2007) Hatay Yöresinde Buğdaydan Sonra II. Ürün Olarak Yetiştirilmeye Uygun Pamuk (Gossypium hirsutum L.) Çeşitlerinin Belirlenmesi. Türkiye VII. Tarla Bitkileri Kongresi, 25-27 Haziran 2007, Erzurum, 1: 736-739. 